\title{
HOMOGENEITY ALONG Cl-COMPENSATED THM GROWN CdTe INGOT
}

\author{
NGO-TICH-PHUOC, G. M. MARTIN, C. BELIN and E. FABRE \\ Laboratoire d'Electronique et de Physique Appliquée, 3, avenue Descartes 94450 Limeil-Brevannes, France
}

Résumé. - On a utilisé différentes techniques expérimentales (courant thermostimulé, temps de vol des porteurs, détection nucléaire) en vue de caractériser des cristaux de tellurure de cadmium préparés par la méthode THM et compensés de différentes manières par le chlore. On constate que la concentration nette d'impuretés croît du début vers l'extrêmité du lingot. On suggère que ceci résulte de la ségrégation d'impuretés résiduelles.

Abstract. - Different characterization techniques (TSC, time of flight, nuclear detection) have been used for assessment of Cl-compensated THM grown crystals, in which the chlorine was introduced in various manners. It is observed that the net carrier concentration increases from the beginning to the end of the ingots. Suggestion is made that this may result from background impurities segregation.

1. Introduction. - High resistivity CdTe is believed to present some potentialities as a material for $\gamma$-rays detection at room temperature, and has been extensively studied for the last few years towards that aim [1-6].

Different growth methods can be used, and halogens can be added in order to compensate the material, thus getting higher resistivity (lowering free carrier concentration, in the range $10^{11}-10^{13} \mathrm{~cm}^{-3}$ ).

Up-to-now, little has been reported about the homogeneity of the electronic properties along a whole ingot [7], even though investigations on the variations of thermodynamic conditions during the growth have been carried out [8-9].

This paper presents an assessment of Cl-compensated, THM grown CdTe ingots : emphasis has been stressed on the homogeneity of carrier concentration and impurity levels involving chlorine, from the beginning to the end of a given ingot. Two ways of chlorine incorporation have been used : either $\mathrm{Cl}$-doping of the starting material before THM, or Cl-doping of the Te zone during the THM process. The ingots are grown at $720^{\circ} \mathrm{C}$ and are about 40 to $50 \mathrm{~mm}$ long and $15 \mathrm{~mm}$ in diameter.

2. $\left(\mathbf{N}_{\mathrm{A}}-\mathbf{N}_{\mathbf{D}}\right)$ variations, as determined by $\gamma$-rays detection measurements. - It is known that the $\gamma$-rays detection efficiency only involves the so-called active volume of the detector made of the depleted region, underneath a reverse biased Schottky contact. In our case, Schottky contacts were made from $\mathrm{Au}$ or $\mathrm{Al}$ evaporation.

By monitoring this detection efficiency for different biasses, it is then possible to estimate the corresponding depleted thickness and therefore the net ionized carrier concentration $\left(N_{\mathrm{A}}-N_{\mathrm{D}}\right)$ [10-11]. This method is especially useful for high resistivity materials, for which it is difficult to make ohmic contact and to carry out reliable Hall effect measurements. Similarly, capacitance measurements are not possible. Experimentally, $800 \mu \mathrm{m}$ thick detectors are used for recording $\gamma$-spectra from a ${ }^{57} \mathrm{Co}$ source; the number of counts under the $122 \mathrm{keV}$ photopeak are plotted against the square root of the applied bias, as shown in figure $1 .\left(N_{\mathrm{A}}-N_{\mathrm{D}}\right)$ can be estimated from the slope of the curve at low voltages, as well as from the voltage for which the

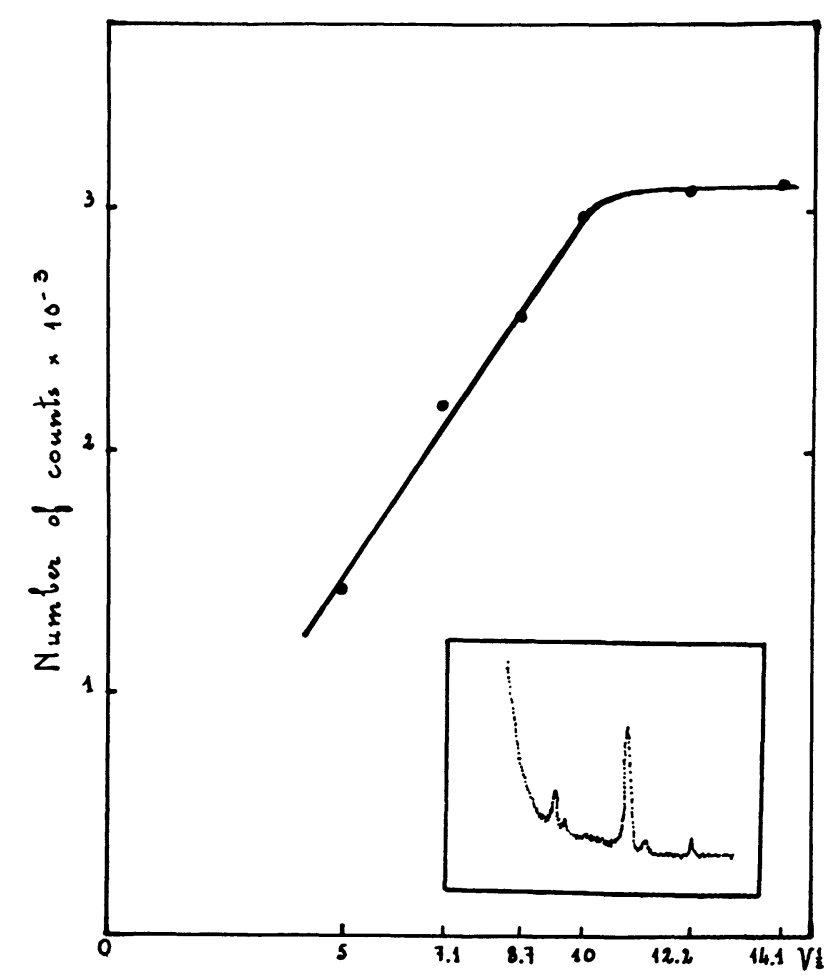

Fig. 1. - Number of counts under the $122 \mathrm{keV}$ photopeak, as a function of the square root of the applied bias. The insert shows the $\gamma$-spectrum recorded from a 57 Co source : FWHM $=$ $6.5 \mathrm{keV}$, applied bias $=100 \mathrm{~V}$. 
detection efficiency saturates. These last conditions correspond to full depletion through the whole thickness.

Using this way of determination, we have investigated several ingots over their whole length. Figure 2

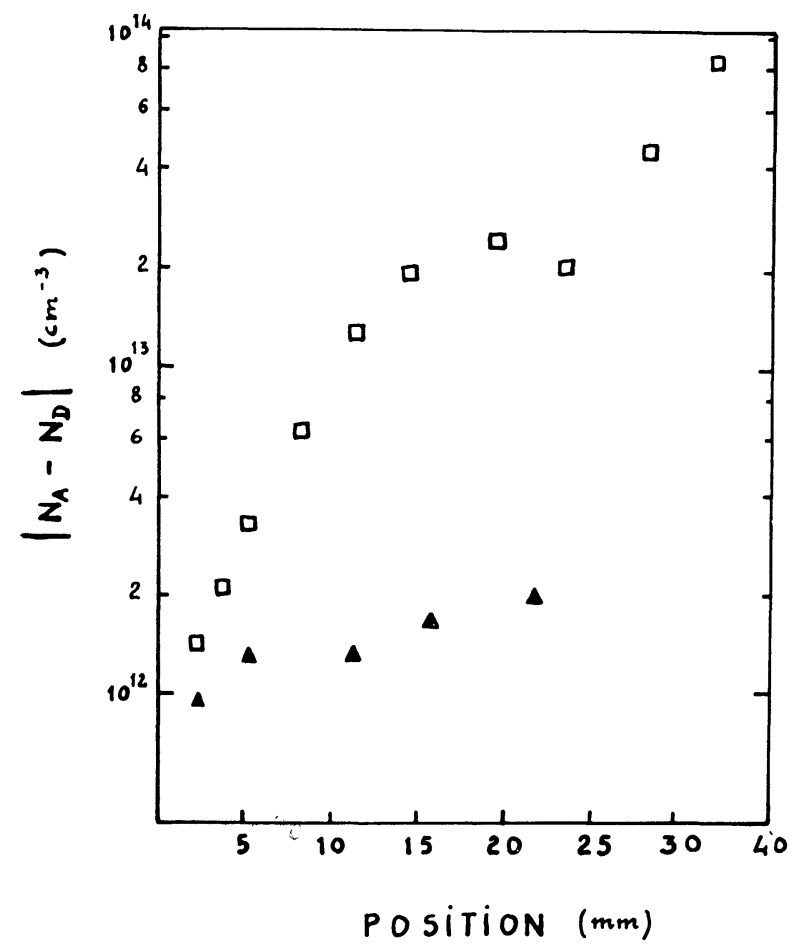

Fig. 2. - Plots of $\left(N_{\mathrm{A}}-N_{\mathrm{D}}\right)$ as a function of the position from the beginning of two THM grown ingots, Cl-doped during THM process.

plots $\left(N_{\mathrm{A}}-N_{\mathrm{D}}\right)$ as a function of the position in two ingots which have been Cl-compensated during THM growth. Quite similar curves can be obtained with ingots for which $\mathrm{Cl}$-compensation has been made in the starting material before THM. $\left(N_{\mathrm{A}}-N_{\mathrm{D}}\right)$ always increases from the beginning to the end of an ingot, but the corresponding slope can be quite different : for instance $\left(N_{\mathrm{A}}-N_{\mathrm{D}}\right)$ is twice its initial value after $20 \mathrm{~mm}$ of growth in case 1 and 10 times in case 2 . At the same time, no degradation of the FWHM resolution is observed through the whole length of the ingot; typical values are FWHM $\sim 7 \mathrm{keV}$ for $122 \mathrm{keV}$ photopeak.

3. Fermi level variations, as determined by TSC measurements. - It has been demonstrated that TSC technique can be a powerful method for deep levels assessment in semiconductors. It enables spectroscopy of traps, and in some cases, a rough estimation of Fermi level position in highly resistive material [12]. With respect to this last application, let us consider the band diagram for a Schottky contact, onto p-type $\mathrm{CdTe}$, under short circuit conditions (Fig. 3a), and flat band conditions (Fig. $3 b$ ). It is clear that level 1 is filled with holes when a forward bias is applied to nearly flat band conditions. On the other hand level 2 will still completely stay below the Fermi level under such conditions and therefore a light excitation at low temperature is necessary to fill it with holes. From the comparison between the spectra recorded with the two ways of excitation, it is then possible to estimate the Fermi level position.

We have investigated several samples cut at different positions in a same THM ingot. The corresponding TSC spectra have been recorded using bias excitation (Fig. 4a) and light excitation (Fig. 4b).

Table I lists, as a function of the position in the ingot i) the temperature at which the shallowest level peaks up under bias excitation and its corresponding activation energy, ii) the Fermi level estimation by comparison with light excitation, iii) $\left(N_{\mathrm{A}}-N_{\mathrm{D}}\right)$ as determined by $\gamma$-rays measurements, iv) Fermi level position deduced by $\left(N_{\mathrm{A}}-N_{\mathrm{D}}\right)$. Such a table shows that the two determinations of Fermi level are in good

(a)

(b)

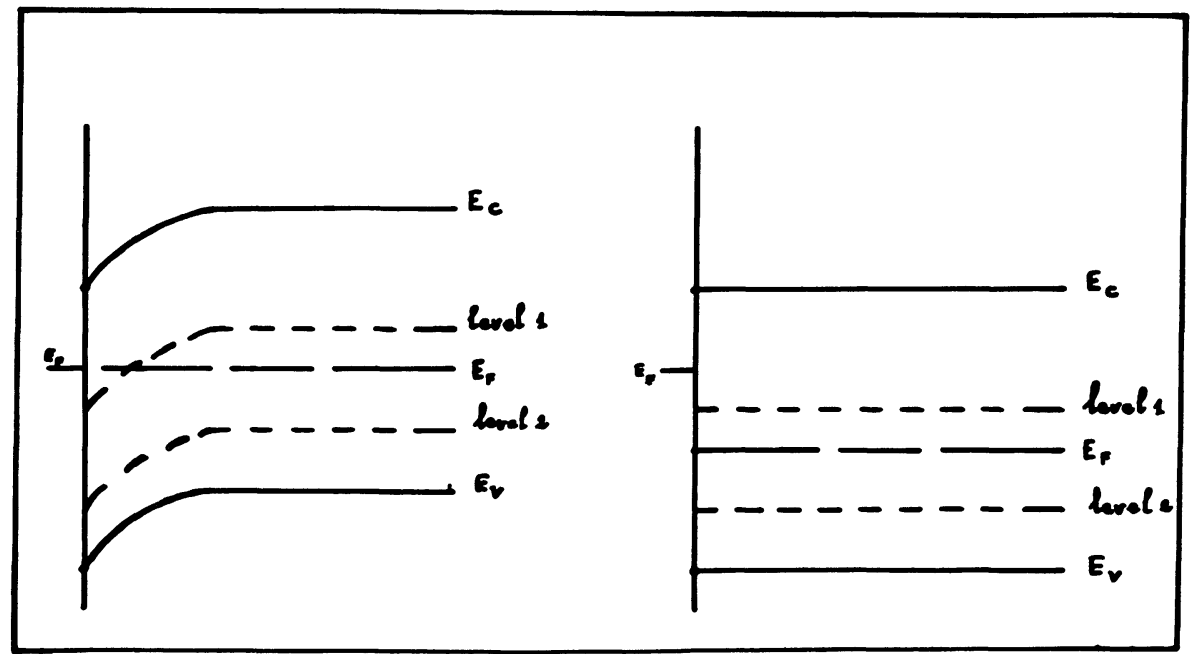

Fig. 3. - Band diagram at a Schottky barrier under : a) short-circuit condition and $b$ ) flat band condition when forward bias is applied. 


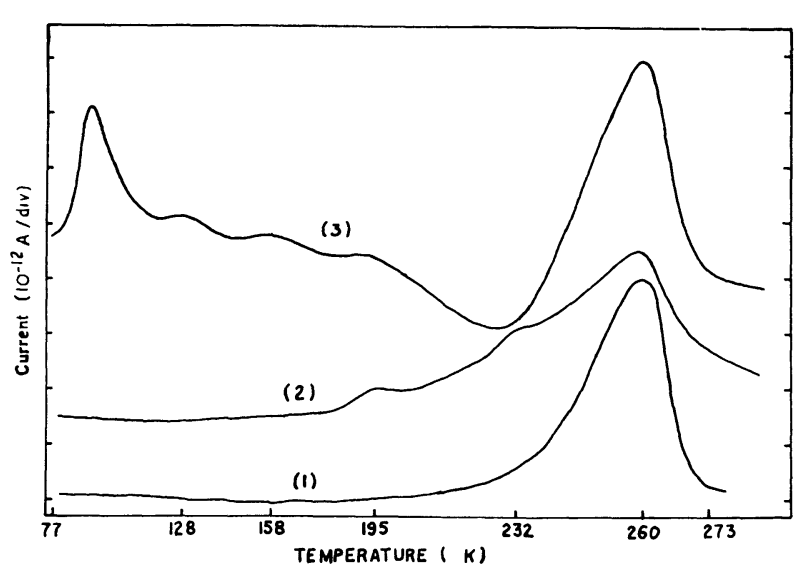

(a)

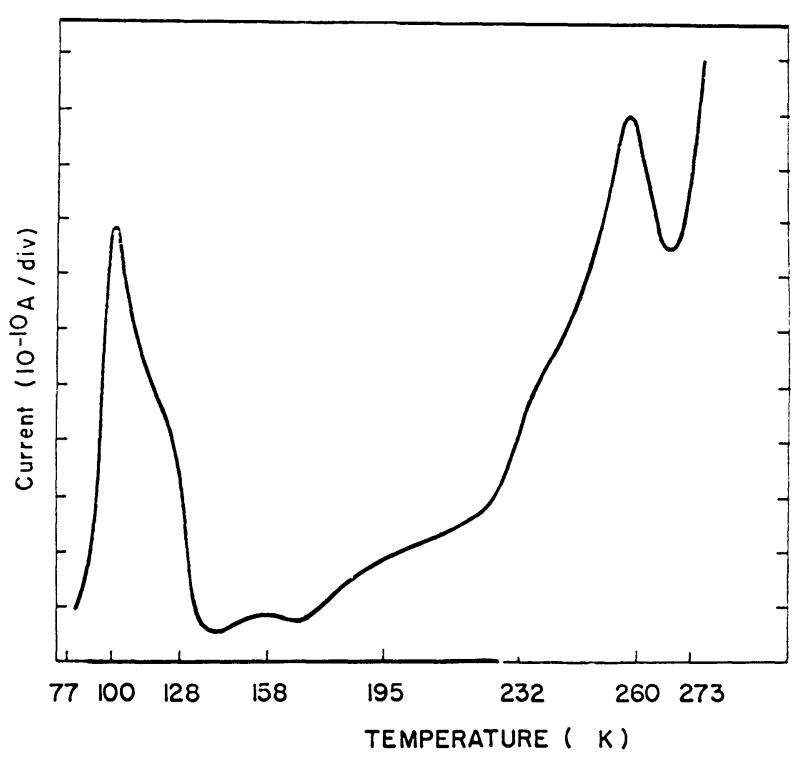

(b)

FIG. 4. - a) TSC spectra recorded under bias excitation conditions from samples cut at three different positions : beginning (sample 1), middle (sample 2), end (sample 3) of an ingot. b) TSC spectrum recorded from sample 1 (used in Fig. 4a) under light excitation conditions.

agreement. TSC measurements are then useful for homogeneity assessment along an ingot and even present the advantage over the methods mentioned in first paragraph of yielding more reliable data, especially with samples having high leakage current.

Table I clearly shows a shift of Fermi level position towards valence band in material cut from the beginning to the end of an ingot.

4. Time of flight measurements. - Electron and hole mobilities have been measured as a function of temperature using time of flight experiment. It has been demonstrated that computer fitting of the curves enables to obtain the total ionized impurities concentration $N_{1}$, as well as the characteristic parameters of the level responsible of the multitrapping effect, i. e. its activation energy $E_{\mathrm{T}}$ and concentration $N_{\mathrm{T}}$.

Figure 5 shows an example of fitting for electrons (Fig. 5a) and for holes (Fig. 5b). Table II lists the estimated values of $N_{\mathrm{l}}, N_{\mathrm{Te}}$ and $E_{\mathrm{Te}}$ from electron

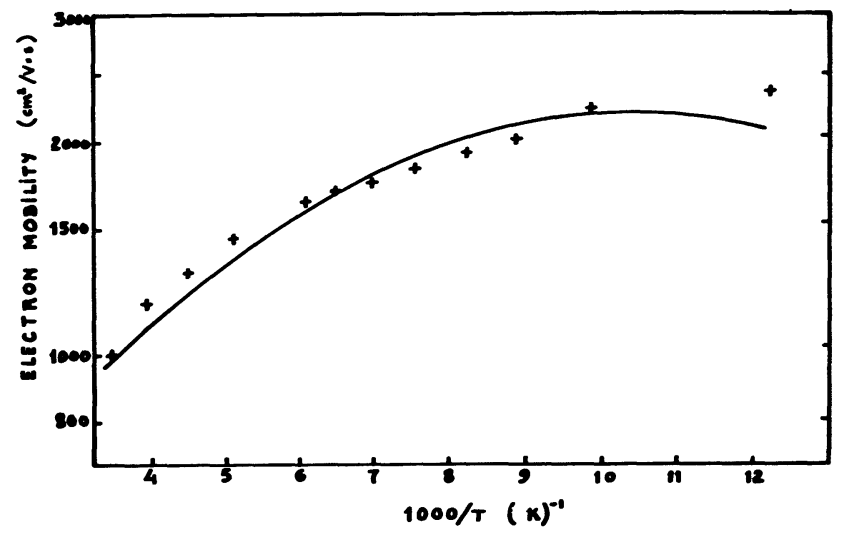

(a)

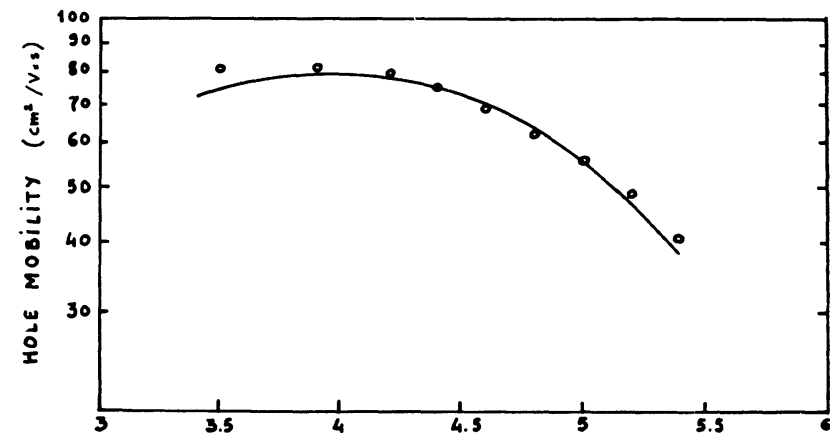

(b)

FIG. 5. - $-a$ ) electron mobility and $b$ ) hole mobility as a function of $1 / T$ recorded from a sample cut in the middle of the same ingot used in figure 4. curve $a$ : sample thickness = $640 \mu \mathrm{m}, E=4700 \mathrm{~V} / \mathrm{cm}$, curve $b:$ sample thickness $=472 \mu \mathrm{m}$, $E=5000 \mathrm{~V} / \mathrm{cm}$

\section{TABLE I}

Comparative results on Fermi level position, as determined by nuclear detection measurements (columns I and III) or using TSC method (columns II and IV), for three samples cut at different positions in an ingot.

$T_{\mathrm{M}}$ of the shallower detected peak

Free carrier density

(B. E. condition

$\left(N_{\mathrm{A}}-N_{\mathrm{D}}\right)\left(\mathrm{cm}^{-3}\right)$ measured with TSC

$$
E_{\mathrm{F}} \text { calculated }
$$

from $N_{\mathrm{A}}-N_{\mathrm{D}}(\mathrm{eV})$

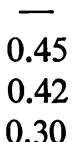

0.45
0.42

0.30

$$
E_{\mathrm{F}} \text { from TSC }
$$$$
\text { (eV) }
$$

$\begin{array}{lll}3 \times 10^{11} & 260 \mathrm{~K} & 0.45 \\ 1 \times 10^{12} & 195 \mathrm{~K} & 0.42 \\ 2 \times 10^{14} & 130 \mathrm{~K} & 0.30\end{array}$

$130 \mathrm{~K}$

$$
\begin{aligned}
& 0.47 \leqslant E_{\mathrm{F}} \leqslant 0.53 \\
& 0.35 \leqslant E_{\mathrm{F}} \leqslant 0.40 \\
& 0.25 \leqslant E_{\mathrm{F}} \leqslant 0.35
\end{aligned}
$$

Position from the beginning of the ingot $(\mathrm{mm})$ 


\section{TABLE II}

Activation energy $E_{\mathrm{Te}}, E_{\mathrm{Th}}$, and concentration $N_{\mathrm{Te}}$, $N_{\text {Th }}$ of the levels responsible for the reduced mobility of electrons and holes, respectively, as determined by computer fitting of mobility versus $1 / T$ curves. In the case of the first sample, it is only possible to give an upper limit for the $N_{\mathrm{Te}}$ value, and $E_{\mathrm{Te}}$ cannot be determined.

\begin{tabular}{|c|c|c|c|c|c|}
\hline $\begin{array}{l}\text { Position } \\
\text { from the } \\
\text { beginning } \\
\text { of the } \\
\text { ingot } \\
\text { (mm) }\end{array}$ & $\begin{array}{l}E_{\mathrm{Th}} \\
(\mathrm{eV})\end{array}$ & $\begin{array}{c}N_{\text {Th }} \\
\left(\mathrm{cm}^{-3}\right)\end{array}$ & $\begin{array}{l}E_{\mathrm{Te}} \\
(\mathrm{eV})\end{array}$ & $\begin{array}{c}N_{\mathrm{Te}} \\
\left(\mathrm{cm}^{-3}\right)\end{array}$ & $\begin{array}{l}N_{\mathrm{I}} \\
\left(\mathrm{cm}^{-3}\right)\end{array}$ \\
\hline $\overrightarrow{13}$ & $\overline{0.155}$ & $1 \overline{\times 1015}$ & 一 & $\leqslant \overline{10}^{15}$ & $0.8 \overline{\times} 10^{17}$ \\
\hline 35 & 0.145 & $3.5 \times 10^{15}$ & 0.025 & $2.5 \times 10^{15}$ & $1.1 \times 10^{17}$ \\
\hline
\end{tabular}

mobility curve, $N_{\text {Th }}$ and $E_{\text {th }}$ from hole mobility curve, at two different positions in the ingot, as deduced from this fitting.

As it has been noticed by Canali et al. [13], concentrations of the acceptor at $E_{\mathrm{v}}+0.145 \mathrm{eV}$ is roughly the same as the one of the donor at $E_{\mathrm{c}}-0.025 \mathrm{eV}$. But concentration of total ionized impurities is extremely high, in the $10^{17} \mathrm{~cm}^{-3}$ range.

It is worth noticing that these two levels have been related to the cadmium vacancy-chlorine complex and a donor involving chlorine respectively.

5. Conclusion. - Different techniques have been used to assess ingots through their whole length. The main conclusions are :

- The detection efficiency at a given bias decreases from the beginning to the end of a given ingot, due to an increase of $N_{\mathrm{A}}-N_{\mathrm{D}}$.

- Even in the case of high detection efficiency, the FWHM remains good (6 to $7 \mathrm{keV}$ at $122 \mathrm{keV}$ ).

- This behaviour does not depend upon the two ways of chlorine doping, but the net ionized impurity concentration seems to be governed by background impurities and their segregation during the growth.

- Time of flight results are in good agreement with the self-compensation model developped by Canali.

- TSC technique appears to be quite useful for the study of high resistivity $\mathrm{CdTe}$, since it not only yields a spectroscopy of deep levels but also a rough estimation of Fermi level position.

\section{References}

[1] Serreze, H. B., Entine, G., Bell, R. O., Wald, F. V., IEEE, NS 21 (1974) 404.

[2] Zanio, K., Krajenbrink, F., Montano, H., IEEE, NS 21 (1974) 315.

[3] Siffert, P., Berger, J., Scharager, C., Cornet, A., Stuck, R. and Bell, R. O., Serreze, H. B., Wald, F. V., IEEE, NS 23 (1976) 159.

[4] Triboulet, R., Cornet, A., Marfaing, Y., Siffert, P., J. Appl. Phys. 45 (1974) 2759.

[5] Taguchi, T., Shirafuji, J., InUishi, Y., Japan. J. Appl. Phys. 13 (1974) 1169.
[6] Tranchart, J. C., Bach, P., J. Cryst. Growth 32 (1976) 8.

[7] Triboulet, R., Marfaing, Y., J. Electrochem. Soc. 120 (1973) 1260.

[8] Bell, R. O., J. Electrochem. Soc. 121 (1974) 1366.

[9] Wald, F. V., Bell, R. O., J. Cryst. Growth 30 (1975) 29.

[10] Malm, H. L., Martini, M., IEEE, NS 21 (1974) 322.

[11] Fabre, E., Ngo-Tich-Phuoc, Martin, G. M., Ortéga, F., IEEE, NS 23 (1976) 182.

[12] Martin, G. M., Fogarassy, E., Fabre, E., J. Appl. Phys. 47 (1976) 264.

[13] Canali, C., Ottaviani, G. and Bell, R. O., Wald, F. V., J. Phys. Chem. Solids 35 (1974) 1405. 